\title{
Örgütlerde Cinselliğin Düzen Bozucu ve Düzen Kurucu Rolünün Eros ve Oyun Açısından İncelenmesi*
}

\author{
Analysing the Destructive and Constructive Roles of Sexuality in \\ Organizations within Eros and Play
}

Alper ASLAN ${ }^{1}$

\begin{abstract}
Özet
Ana akım örgüt yaklaşımları, Logos mantığı kapsamında, cinselliği düzen bozucu bir güç olarak görerek örgütlerden yok etmeye çalışmıştır. Buna karşın, cinsellik örgütlerden tamamen yok edilemez. Her örgütte çeşitli cinsellikler ifade edilmektedir. Cinsellik ve Eros bağı sosyal teoride tartışmalı bir konudur. Eros, cinselliğin nitel ve nicel dönüşümü olarak düzen kurucu olabilmektedir. Bu çalışma örgütlerde Eros, oyun ve cinsellik ilişkilerini "düzen bozucu" ve düzen kurucu" işlevleri çerçevesinde incelemiştir.
\end{abstract}

Anahtar Kelimeler: Örgütlerde cinsellik, Eros, Marcuse, oyun.

\section{GiRiş}

Kökenleri 16. yüzyıl "Rönesans Hümanizmi”ne ve 17. yüzyıldaki bilimsel ve felsefi değişikliklere dayanan (Toulmin, 2002: 39, 115) modernlik "toplumsal yaşam ve örgütlenme biçimlerin"de (Giddens, 2004: 11), Logos mantığının güç kazanmasını ifade eder (Bauman, 2003: 26; Toulmin, 2002: 151; Wang, 2000: 27-42). Logos mantığı; ussallık, zihin, düzen, denetim ve çalışma unsurlarıyla ilgilidir. Logos mantığı; ikiciliğe, hiyerarşiye, ayrımlamaya ve sınır çizmeye dayanan bir düzen kurar (Bauman, 2003: 9-30; Wagner, 1996: 68). Logos; olguları, kavramları, ilişkileri, bireyleri vb. "ussal"-"ussal olmayan" olarak "ayırır, sınıflar, parçalar" (Koçak, 2008: 40-42; ayrıca bkz. Plumwood, 2004: 6398). Bu ayırmaysa, "ötekileştirerek ve olumsuzlayarak" bir tarafın olumlandığı, diğerininse olumsuzlandığı ikicilikler doğurur (Plumwood, 2004: 11).

Eros mantığı, "her bir bireyin içindeki en derin, en güçlü, en zengin sevgi tutkusunun fiziksel, duygusal ve ruhani olarak ifadesi" olarak tanımlanabilir (Lorde,

\begin{abstract}
Within the Logos logic, mainstream organization studies see sexuality as a force of destructive which should be eliminated from the organizations. However, organizations cannot be totally desexualized. In every organization diverse sexualities are expressed. The relation of sexuality and Eros is controversial in social theory. Although, Eros depends on sexuality, Eros can be conceptualized as constructive within the qualitative and quantitative transformation of sexuality. This study analyses the relations of Eros, play and sexuality within their roles as "destructive" and "constructive" in organizations.
\end{abstract}

Key Words: Sexuality in organizations, Eros, Marcuse, play.

1984'den aktaran Carr, 2003: 9). Eros mantığı; duygu, beden, haz, sevgi, cinselliği ifade eder (Wang, 2000; Bell ve Sinclair, 2014). Eros bireyi kendi doğasıyla, diğer bireylerle ve doğayla birleştiren güçtür (Bowles, 1993; Marcuse, 1998; Shilling ve Mellor, 2010).

Logos mantığı modernlikte düzen kurucu olarak görülür. Bu yönde, Eros mantığı modernlikle toplumsal yaşamın birçok alanından baskılanmıştır (Bell ve Sinclair 2014; Wang, 2000). Örgütler, Logos mantığının egemen olduğu en önemli kurumlardır. Modern örgütlerde ussallık, düzen ve denetim unsurlarına önem verilir. Bundan dolayı, modern örgütlerden cinsellik, oyun, duygu gibi unsurlar uzaklaştırılmaya çalışılmıştır (Hancock ve Tyler, 2001; Schultz, 2003). Örgüt çalışmaları yazınında, genellikle, cinsellik "düzen bozucu" olarak kavramsallaştırılmıştır (Aquino vd., 2014; Fleming, 2007; Schultz, 2003; Zelizer, 2009). Söz konusu yazın cinselliğin nitel ve nicel bir dönüşümü olan Eros (Marcuse, 1998: 150) ve onun cinsellikle ilişkisi üzerinde - özellikle "sosyalleşme olarak oyun" kapsamında (bkz. Simmel, 
2009: 134-146) - yeterince durmamıştır (Bell ve Sinclair, 2014).

Bu çalışma, ilk önce cinselliği düzen bozucu gören belli başlı çalışmalar üzerinde durmuştur. Daha sonra, çalışma cinselliğin düzen kuruculuğu kapsamında Eros ve cinsellik ilişkisini ve söz konusu ilişkiyi örgütler için değerlendirmiştir. Son olarak da çalışmada örgütlerde cinselliği inceleyecek çalışmaların "çalışma pratikleri"ni ele almaları gerektiği vurgulanmıştır.

\section{2.ÖRGÜTLERDE DÜZEN BOZUCU OLARAK CINSELLIK}

Logos mantığı; ussal-duyusal, çalışma-oyun, üretim-tüketim, kamu-özel, ikiciliklerine dayanır (Wang, 2000). Logos mantığında kamusal alan olarak örgütler, ussallığın mutlak egemenliğinde, bireylerin (verimli) çalışarak üretim yaptıkları alanlar olarak ele alınır. Logos mantığında cinsellik örgütlerde "düzen bozucu" olarak ele alınarak verimsizlik, kayırmacılık, cinsel taciz gibi olumsuzlukların nedeni olarak görülmüştür; bundan dolayı örgütlerden oyun, duygular, cinsellik gibi unsurlar yok edilmeye çalışılmıştır. (Aquino vd., 2014; Burrell, 1984; Fleming, 2007; Hearn ve Parkin, 1995).

Klasik örgüt yaklaşımlarından "bilimsel yönetim teorisi" ve "bürokrasi teorisi, Logos'un örgütlerde baskın olması gerektiğini savunurlar. Söz konusu teoriler, cinsellikle doğrudan ilgilenmeseler de yönetim ve örgütün nasıl olması gerektiğiyle ilgili düşünceleri cinselliğe karşı tutumlarını açığa serer (Schultz, 2003: 2073). Bu tutum, cinselliği örgütlerden tamamen yok etmektir (Burrell, 1984: 98-99; Schultz, 2003: 2072-2073). Zihin ve beden ikiciliğine dayanan bilimsel yönetim yaklaşımında tüm çalışma pratiklerinin planlanması yöneticiler tarafından yapılır. Çalışanların sosyallikleri, bireysellikleri yok sayılır ve onlardan beklenen yalnızca planlara uymalarıdır. Bilimsel yönetim yaklaşımında örgütlerde verimlilik karşıtı görülen oyalanmalara, duygulara ve cinselliğe yer yoktur. Taylor, çalışanların tüm bedensel hareketlerini standartlaştırarak, işi en ufak parçasına ayırarak, üretim karşıtı gördüğü cinsellik, oyalanma, oyun vb. kavramları denetlemeye çalışmıştır (Schultz, 2003: 2064).

Bürokrasi teorisi de (bkz. Weber, 2006: 290-324) örgütlerden duygular, oyunlar, cinsellik gibi ussallık dışı unsurları uzaklaştırmaya odaklanmıştır (Burrell, 1984: 98-99):
“Bürokrasi ne denli 'insanlıktan uzaklaşırsa, o denli kusursuz gelişir; resmi işlerden sevgi, nefret ve tüm hesaplanamaz kişisel, irrasyonel ve duygusal ögeleri ne denli ayıklanırsa, bürokrasi asıl niteliğine o denli yaklaşır" (Weber, 2006: 310; ayrıca bkz. Schultz, 2003: 2073).

Klasik yönetim anlayışlarının cinselliği denetleme ilgisiyse yalnızca örgüt içerisinde sınırlı kalmayarak örgüt dışına, özel alana ve serbest zamana da taşmıştır. Bu kapsamda Fordizm çalışanların cinselliklerini örgüt dışında da çalışma zamanında verimsizliğe yol açmaması için denetlemiştir (Hancock ve Tyler, 2001: 156-157).

1980 sonrası bazı örgütlerdeki üretim pratiklerinde esneklikler çalışanların cinselliklerini yansıtma olanakları arttırmasına karşın (Fleming, 2007), günümüzde de örgütlerde cinsellik yazını ağırlıklı olarak cinselliği düzen bozucu olarak görmektedir. Bu kapsamda en önemli iki yazın "romantik ilişkiler" ve "cinsel taciz" yazınıdır (Aquino vd., 2014; Williams ve diğerleri, 1999).

Quinn (1977) romantik ilişkileri "aynı örgütteki iki kişi arasındaki ilişkinin, üçüncü kişiler tarafından cinsel çekim kapsamında algılanması" olarak tanımlamıştır (s. 30). Örgütlerde romantik ilişkiler yazını, ağırlıklı olarak, yöneticilerin ilgisini yansıtır ve örgütten cinselliği uzaklaştırmaya çalışır (Boyd, 2010). Söz konusu yazın, örgütlerdeki romantik ilişkilerin nedenleri, etkileri ve yönetimin bu ilişkilere karşı olan tutumları üzerinde durmuştur (bkz. Pierce ve Aguinis, 2009; Wilson, 2015). Williams ve diğerleri (1999), söz konusu yazının cinselliğe karşı olan tutumunun "Freud'un uygarlığın işlerliği için cinselliğin baskılanması gerektiğini savunan düşüncesine dayandığını" belirtmişlerdir (s. 81). Bu düşüncede cinsellik"ussallık karşıtı olarak düzen bozucu, tehlikeli ve denetlenmesi gereken olarak görülür" (Williams ve diğerleri, 1999: 81; ayrıca bkz. Pierce ve Aguinis, 2009: 448). Bu kapsamda, romantik ilişkiler yazını söz konusu ilişkilerin olumsuz etkilerine odaklanmıştır. Romantik ilişkilerin olumsuz etkileri kapsamında kayırmacılık, cinsel taciz, azalan verimlilik, azalan moral, azalan iletişim, artan dedikodu, kıskançlık, kızgınlık ve şikâyet vb. belirtilmiştir (Pierce ve Aguinis, 2009; Powell, 2001; Quinn 1977; Riach ve Wilson, 2007; Zelizer, 2009).

Örgütlerde cinselliği düzen bozucu olarak gören diğer önemli bir yazın genellikle feminist görüşler 
etrafında örgütlenen cinsel taciz yazınıdır (Aquino vd., 2014; Hearn, 2011). Feministler, örgütlerde ussallığın erillikle ilişkilendirildiğini, erkeklerin otorite ve gücü ellerinde tuttuklarını, kadınların ussallık karşıtı ve özel alana ait görülerek marjinal konumlara itildiklerini belirtirler (Brewis ve diğerleri, 1997: 1282; Martin, 2006: 267). Bunun sonucunda örgütlerde kadınlar, erkeklere göre "ücret, terfi ve takdir edilme" unsurlarında dezavantajlıdırlar (Martin, 2000: 208).

Feministler; sekreterlik, hemşirelik, garsonluk gibi işlerin kadınlara atfedilen değerlerle (örneğin; şefkatli olma, pasif olma, duygusal olma gibi) ilişkilendirildiğini ve bu işlerde kadın cinselliğinin öne çıkarıldığını da belirtirler (Adkins, 1995; Ely ve Padavic, 2007). Bununla birlikte, bazı işler de (itfaiyecilik, yöneticilik, mühendislik vb.) eril görülmektedir. Erkekler eril egemen işlere kadınların girmesini işin erilliğini tehdit olarak algılayarak, erilliği ve eril cinselliği kadınların aleyhine kullanabilmektedirler (Ackroyd ve Thompson, 1999: 133-134; Britton, 1997: 799-800). Örgütlerdeki eril egemenlik, kadın çalışanların görünümleri, hal ve hareketleri üzerinde disiplin sağlamaktadır (Trethewey, 1999). Bu disiplin, kadın cinselliğini ön plana çıkararak kadın çalışanların cinsel tacize maruz kalmalarını arttırmaktadır (Adkins, 1995). Kadın çalışanlar, cinsiyet ve cinsel ayrımcılığına uğramamak için daha eril görünme çabalarına girmektedirler (Brewis vd., 1997; Trethewey, 1999). Özetle, feminist yazın eril cinselliği denetimden çıkan, baskıcı ve olumsuz olarak kavramsallaştırmıştır (Aquino vd., 2014; Pringle, 2005; Schultz, 2003). Buna karşın, örgütlerde cinselliği tamamen düzen bozucu görmek tek taraflı bir değerlendirmedir. Bir sonraki kısımda örgütlerde cinselliğin olumlu olarak kavramsallaştırılması üzerinde durulacaktır.

\section{CINSELLIK VE EROS'UN DÜZEN KURUCULUĞU}

Sosyal teoride Eros'un kavramsallaştırılması onun düzen kurma, cinsellikve ussallıkla olanilişkilerinegöre farklılaşmaktadır (Shilling ve Mellor, 2010). Örneğin, Freud (2004), uygarlığın, Eros (yaşam içgüdüsü) ve Thanatos'un (ölüm içgüdülerinin) "yüceltilerek bastırılmasıyla" olanaklı olduğunu savunur. Freud'a (2004) göre yaşam güdüleri yüceltilerek bastırılır; bastırılan bu güçlerse aşılamadıklarından huzursuzluk yaratır. Bu yönde "uygarlık" ya da "modern dünya" hoşnutsuzluklarıyla vardır.

Shilling ve Mellor (2010), Weber ve Bataille'in, Eros'u, Logos egemenliğindeki modernlikte bir anlam kaynağı ve bireyleri birleştirici olarak gördüklerini belirtmişlerdir. Buna karşın, Shilling ve Mellor (2010), Weber'in, Eros'un düzen kurucu işlevine karşı belirsiz bir tutum sergilediğini belirtmişlerdir. Weber, Eros'un ikili ilişkilerle sınırlı kalabilmesi ve tehlikeli sonuçlar doğurabilmesi olasılığına karşı onun özel yaşam alanında tutulmasını ve dinsel düzenlemeyle denetlenmesini savunur (Shilling ve Mellor, 2010: 439; ayrica bkz. Burrell, 1992: 76-77). Bataille'a göre, Eros bireye sonsuzluk hissi vererek tüm evrenle birleştirir (Shilling ve Mellor, 2010: 442). $\mathrm{Bu}$ ise beraberinde yaşam güdüsü olan Eros'un ölüm içgüdüsüyle birleşmesini ve bireyselliğin kaybolmasını getirir (Shilling, 1997: 200; Zilbersheid, 2009b: 83). Bataille, aynı zamanda Eros'u eril egemen görerek, bu durumun kadınların mağduriyetiyle sonuçlanabileceğini belirtir (Shilling ve Mellor, 2010: 442).

Cinselliğin ve onun "nitel ve nicel büyümesi" olan Eros'un (Marcuse, 1998: 150) özgürleşmeyle ilişkisiyle eleştirel teorinin önemli temsilcisi Frankfurt Okulu da ilgilenmiştir (Rickert, 1986: 352). Frankfurt Okulu farklı zamanlarda birçok alanda (felsefe, bilim, siyaset, sanat, estetik gibi) çalışmalar yürütmüştür. Frankfurt Okulu'nun modernliğe yönelik eleştirileri birçok farklı konuya (Logos mantığı, modern bilim, kitle kültürü vb.) dokunmaktadır (Jay, 2005). Frankfurt Okulu, baskıcı sosyal yapıların kaldırılarak, birey(ler)in "temel insani ilişkilerini karşılayacakları ve insani potansiyellerini geliştirecekleri yeni üretim ilişkilerinin, yeni toplumsal ilişkilerin yaratılmasını" amaçlar (Kellner, 2006: 149). Bu yönde, Frankfurt Okulu temsilcilerinden özellikle Reich, Fromm ve Marcuse cinsellik ve Eros üzerinde durmuşlardır.

Reich, cinsel boşalmanın önemine odaklanarak, cinselliği ve özgürlüğü cinsel birleşmeyle sınırlamıştır (Brewis ve Linstead, 2000: 159). Reich'e göre cinselliğin özgürce yaşanması durumunda "cinsel ahlak" doğal olarak oluşacaktır (Brewis ve Linstead, 2000: 158). Marcuse, cinsellik ve ussallığı karşıt görmemesiyle Reich'le aynı tarafta olmasına karşın (Brewis ve Linstead, 2000: 158), Reich'in "özgürlükteki ilerlemeyi cinselliğin salt bir salıverilişi olarak görmesini eleştirir" (Chodorow, 1985: 277; Marcuse, 1998: 171). Marcuse'a göre cinselliğin yalnızca cinsel/genital birleşmeyle sınırlandırıması insan bedeninin ve diğer insan etkinliklerinin erotik ve özgürleştirici potansiyelini ihmal etmektedir (Brewis ve Linstead, 2000: 160).

Fromm (1997), Reich'in özgürlüğü cinsel birleşmeye indirgemesine karşıdır. Fromm'un 
Eros kavramsallaştırması biyolojik olmaktan çok sosyaldir; sevgiye dayanır. Fromm, Freud'un libido teorisini reddederek, Eros ve cinsellik arasındaki bağı koparmıştır (Rickert, 1986: 361). Marcuse (1998), bu durumun özgürleşmeyi yalnızca bilinç boyutuyla sınırladığını, bilinçdışı ve maddesel boyutları ihmal ettiğini (s. 186), dolayısıyla, özgürlük için tehlikeli ve özgürlüğün temelini sağlayan cinselliği yok saydığını belirtmiştir (ss. 172-173; karşı sav için bkz. Rickert, 1986). Marcuse, özgürleşmenin yalnızca bilinçle değil aynı zamanda insan doğasına (cinselliğe) içkin olduğunu savunur (Chodorow, 1985: 273; Rickert, 1986: 366).

Marcuse (1998), Marx ve Freud'u sentezlediği çalışmasında çalışma ve oyunun, çalışma ve hazzın, ussallık ve duyusalın/bedenin, bastırılmadan yüceltilebilmiş Eros'un ve uygarlığın, karşıt olmadığını belirtmiştir (ayrıca bkz. Zilbersheid, 2009a; 2009b). Marcuse'un Eros teorisi baskılanmadan yüceltilmiş Eros'un uygarlık kurabilme gücüne ve Eros'un içinde ussallık barındırmasına dayanır. Marcuse, çalışmayı insanın özünü gerçekleştirmesinin yolu görerek Marx'la aynı görüştedir (Jay, 2005: 115). Marcuse'a (1998) göre bireyleri ve toplumu özgürleştirecek çalışma, araçsal olmayan ve birleştirici olan Eros mantığındaki çalışmadır (s. 50). Logos mantığındaki çalışmanın temel özellikleri araçsallık ve ayırıcılıktır. Belirli bir amaca ulaşmak için araçsal olarak yapılan, bireylere haz vermeyen ve onların öz-gelişimlerini sağlamayan bu çalışmada, en ufak ayrıntısına kadar iş bölümü uygulanmakta ve çalışma pratikleri verimlilik ölçütüne göre değerlendirilmektedir (Dant, 2003: 49). Marx'a göre, böyle bir çalışma bireyin kendisine, doğaya ve diğer bireylere karşı yabancılaşması, diğer bir deyişle, kendisinden, doğadan ve diğerlerinden ayrılmasıdır (Dant, 2003: 9). İlgili çalışma bireyin doğasının, doğanın, diğer bireylerin sömürülmesini, özgün olmayan çalışma ilişkilerini ve pratiklerini içerir (Zilbersheid, 2009a: 409-412).

Marcuse (1998) da, Logos mantığı egemenliğinde artan işbölümün, çalışmayı bireyler için külfetleştirdiğini belirtmiştir (s. 51). Marcuse (1998), ileri sanayi toplumlarında Logos mantığını yerinden etmenin koşullarının doğduğuna inanır. Marcuse (1998), Freud'dan farklı olarak güdüsel gereksinimlerin özgür doyumunun uygar bir dünyada bastırılmadan olabileceğini savunur. Baskıcı olmayan yüceltmede cinsellik "amacından ne saptırılır ne de engellenir; tersine, hedefine erişmede, daha tam bir doyumu araştırarak onu başkalarına doğru aşar" (Marcuse,
1998: 154). Böylece yüceltilen cinsel güdü "nitel ve nicel olarak büyüyerek"Eros'a dönüşür (Marcuse, 1998: 150). Bu dönüşümle, cinsellik ve ondan elde edilen hazlar cinsel ilişkilerle sınırlanmayacak, tüm bedene, ilişkilere ve tinsel alana yayılabilecektir (Marcuse, 1998: 153). Diğer bir deyişle, Eros'un olanaklılığı için cinsellik bir temel sağlayıııdır (Marcuse, 1998).

Marcuse'a (1998) göre Eros, ussallık karşıtı değildir. Marx'ın "artık değer" kavramından esinlenen Marcuse (1998), "artık baskıyla" uygarlığın işlerliği için bireylerin ve toplumun üzerindeki "vazgeçilmez olanların üstünde ve üzerindeki ek denetimleri" ifade eder (s. 46). Marcuse'a göre "artık baskı"nın olmadığı bir ortamda Eros kendi ussalığını barındırır (Chodorow, 1985: 276). Marcuse (1998), buna "duyusal ussallık" demiştir (s. 164).

Marcuse'a (1998) göre, Eros mantığındaki çalışma araçsal değildir; böyle bir çalışma estetiktir ve kendinde amacını taşıyan "oyun"dur (s. 155). İlgili oyunsal etkinlikte haz kaynağı olan cinsellik"nitelik ve nicelik olarak genişler" ve tüm bedeni, birçok hareketi kapsar (Marcuse, 1998: 150). Eros'un araçsal, sınırlı bir cinselliğe indirgenmesinin kaybolmasıyla, daha önce bireye haz vermeyen bedeni ve hareketleri haz kaynağı olacaktır (Marcuse, 1998: 159). Ayrıca oyunsal etkinlikler bireyin kendisiyle, bedeniyle, doğayla ve diğer insanlarla birleştirir, kaynaştırır (Marcuse, 1998: 50; Sandelands, 2010: 74; Zilbersheid, 2009b).

Marcuse (1997), 1960-1980 sonrası ileri sanayileşmiş dünyada yaşanan cinsel özgürleşmeler hakkındaysa kötümserdir. Marcuse'a (1997) göre ileri sanayileşmiş dünyada cinsellik artık "bir pazar değeri" olarak kullanılmakta ve "[b]ir emek aracı olmaya son vermeksizin, bedene cinsel özelliklerini gündelik çalışma dünyasında ve çalışma ilişkilerinde sergileme izni" verildiğini belirtir (s. 65). Marcuse'a (1997) göre bu sözde cinsel özgürleşme "genel baskı statükosuna karşı olmaktan çok ondan yana çalışır" (s. 65). Bir bakıma, Marcuse ütopik, yapısal ve devrimsel bir Eros kavramsallaştırması yapmış ve Eros'u gündelik yaşamla bağlantılandırmamıştır (Walsh, 2008: 238).

\section{CINSELLIKK VE EROS'UN DÜZEN KURUCULUK VE DÜZEN BOZUCULUK KAPSAMINDA ÖRGÜTLER BAĞLAMINDA DEĞERLENDIRILILMESI}

Burrell (1992), Marcuse'un kavramsallaştırması kapsamında Eros'u cinselliğin nitel ve nicel büyümesi olarak "insanlara ve yaşama karşı daha neşeli daha 
oyunsal bir sosyallik" olarak açıklamıştır (s. 78). Burrell (1992), Marcuse (1997) gibi, 1980 sonrası örgütlerde oyun, eğlence gibi unsurların araçsal kullanımını eleştirmektedir. Burrell (1992), Eros mantığının geleneksel örgüt formlarıla ve yöneticilerin araçsal kullanmasıyla uyumlu olamayacağını, ancak özgürlük, doğa, ortaklık gibi kavramlara önem veren alternatif yapılanmalarla uyumlu olabileceğini belirtmiştir (s. 82). Burrell (1992), Eros mantığını "karnaval" metaforuyla açıklamış ve Eros mantığıyla ya da karnavalla örgütlerdeki geleneksel hiyerarşi ve baskıların yok olacağını, insan ilişkilerinin "haz arama" üzerine kurulacağını, böylece örgütlerin "topluluklar" gibi daha sıcak ilişkilerden oluşacağını belirtmiştir (Burrell, 1992: 79-80). Burrell (1992), cinselliğin oyunsal olarak düzen kuruculuğuna işaret etmiş, oyunsal olmayan cinselliklerin örgütlerde özellikle eril cinselliğinin yansıması olarak düzen bozucu olabileceğini belirtmiştir (s. 84).

Burrell'in (1992) görüşlerine karşın, Brewis ve Linstead(2000),Marcuse'unEroskavramsallaştırmasını cinselliği "cinsel birleşmeden öte kavramsallaştırdığı için olumlu görürler (s. 166); ancak onlara göre Marcuse'un Eros kavramsallaştırması heteroseksüel cinselliğin nitelik ve nicelik değiştirmesine dayandığı için özcü ve temelcidir (Brewis ve Linstead, 2000: 161). Brewis ve Linstead (2000), herhangi bir temele dayanan cinselliğin, özgürleştirme potansiyelini azalttığını ve sonucunda baskıcı olabileceğine dikkat çekerler; örneğin eşcinseller için (ss. 169-171). Ayrıca, Brewis ve Linstead (2000), Bataille'den esinlenerek, Eros ve Thanatos'u (ölüm içgüdüsü), ontolojik olarak yakın görerek, Eros'un örgütlenmemeyi de içerdiğini belirtmişler ve Eros'un örgütlenmenin gereksinim duyduğu amaç, düzen, belirlilik gibi unsurlarla birlikte var olamayacağını vurgulamışlardır (s. 181).

Cinselliğin oyunsal ifadesinin yalnızca alternatif yapılardaki örgütlerde olabileceğini (bkz. Burrell, 1992: 82) ya da örgütlerde cinselliğin Eros kapsamında oyunsal olarak ifade edilemeyeceğini savunmak (bkz. Brewis ve Listead, 2000) bütüncül değerlendirmelerdir. Bütüncül değerlendirmeler, sosyal yaşamdaki direnişleri ve farklı oluşumları göz ardı ederler (Gotham ve Krier, 2008, Riach ve Wilson, 2014). Günümüzde birçok çalışma, örgütlerde cinselliğin olumlu etkilerini belirtmiştir. Bu kapsamda çalışanların sosyalleşmeleri, çalışanların mutluluğu ve bireysel tatminleri, artan bireysel ve örgütsel performans, işi eğlenceli kılma, iş stresini azaltma sayılabilir (Aquino vd., 2014; Erickson, 2010; Lerum,
2004; Riach ve Wilson, 2007; Schultz, 2003; Zelizer, 2009).

Çoğu zaman, örgütlerde cinsellik ne tamamen olumlu ne de tamamen olumsuzdur (Fleming, 2007; Zelizer, 2009). Ayrıca, örgütlerde cinselliğin yönetim amaçları tarafından çalışanları denetlemek için kullanılması da mutlak olmamaktadır (Fleming, 2007). Cinselliğin düzen kuruculuğu ya da düzen bozuculuğunun farklı örgütler ve örgüt içinde farklı çalışanlar açısından ele alınması Eros, cinsellik ve oyun bağlantısının daha kapsamlı değerlendirilmesinde yatmaktadır.

Oyun çalışmaları yazını, oyunun çok farklı etkinliklerden oluşabildiğini vurgulamaktadır; bu kapsamda; sosyalleşme, fantezi, imgelem, şakalar, mizah, dinsel ayinler, kutlamalar, yarışmalar gibi birçok etkinlik oyun ve /ya da oyunsal olabilir (SuttonSmith, 2001). Oyun, belirli etkinliklerle sınırlı değildir (Sutton-Smith, 2001: 174). Oyunun herhangi bir etkinlik ya da pratiği belirtmekten çok en iyi şekilde "zarf" kullanımıyla tanımlanacağı belirtilir (Millar, 1986'dan aktaran Gordon, 2009: 4). Görünürde oyunsal olan her etkinlik oyun olmayabilir ya da farklı zamanlarda yapılan etkinlikler bazen oyunsal olabileceği gibi zorunluluktan da kaynaklanabilir (Beatty ve Torbert, 2003: 245).

Oyun "gereklilik ve yararlıık" alanlarına doğrudan girmez (Huizinga, 20056: 202). Oyunlar başka amaçlar için yapılabilse de, her zaman için kendinde amaçlarını taşırlar (Sutton-Smith, 2001: 78). Oyun, "belirsizlik" özelliğine sahiptir (Sutton-Smith, 2001). Oyun, hem gerçek hem sahte (Mainemelis ve Ronson, 2006: 86) hem ciddi hem ciddi olmayan olabilir. Oyun ve ciddiyet birbirlerine karşıt olmayıp birbirlerinin eşi de değillerdir (Huizinga, 2006: 45; Sandelands, 2010: 76-77).

Cinsellik açısından oyunun belirsizlik özelliği onun "düzen kurucu" potansiyelinin yanında "düzen bozucu" tehlikesini de barındırır (Burrell, 1992: 84; Collinson, 2002). Oyun "neşe, tutku, üzüntü, korku, nefret, kızgınlık" vb. birçok duygunun güvenli ifadesine olanak vermektedir (Mainemelis ve Ronson, 2006: 96). Cinsellik ve onun nitel ve nicel büyümesi olan Eros'la (erotizm) oyun birbirleriyle sıkı bir şekilde bağıntılıdır (Collinson, 2002: 279; Duncan ve diğerleri, 1990: 261; Huizinga, 2006: 67-68; Simmel, 2009: 140). Birçok dilde oynamak, oynaşmak erotik anlamlara sahiptir (Huizinga, 2006: 67). Cinselliğin oyunsal ifadeleri cinsel ilişkilerle sınırlı değildir (Erickson, 2010; 
Marcuse, 1998; Simmel, 2009: 140-141). Huizinga'nın (2006) belirttiği gibi, cinsel ilişkide "eyleminin hazırlanması ve girizgâhı çoğu zaman birçok oyunsal karakter göstermektedir" (s. 67). Simmel (2009) de sosyallik kapsamında karşı cinslerin cilveleşmelerini, oyun olarak değerlendirir.

Örgütlerde cinsellik oyunsal olarak flört ve şaka biçiminde ifade edilebilir. Birçok çalışma bu tür cinsel ifadelerin çalışanlar arasında ilişkileri güçlendirdiğini, iş stresini azalttığını ve işi zevkli kıldığını belirtmiştir (Erickson, 2010; Lerum, 2004; Williams vd., 1999). Örneğin, Erickson (2010) ABD'deki bir restoranda yaptığı araştırma kapsamında cinsel şaka ve flörtlerin çalışanların sosyalleşmelerini ve zevkli bir ortamda çalışmalarını sağladığını vurgulamıştır. Ancak, cinselliğin oyunsal ifadelerine içkin olan belirsizlik, bazen hangi davranışın taciz, hangisinin şaka olduğunun anlaşılmasını da zorlaştırır. Diğer bir deyişle, cinsel şaka ve flörtler baskıcı ve dışlayıcı olabilir (Denissen, 2010; Huizinga, 2006:26; Yelvington, 1996). Örneğin, erkek çalışanlar cinsel mizah ve şakayı kadın çalışanları rencide edebilecek şekilde kullanabilirler (Collinson, 2002). Aynı zamanda, örgütlerde erkek çalışanların yaptıkları masum cinsel şakalar da kadın çalışanlar tarafından taciz olarak değerlendirilebilir (Duncan ve diğerleri, 1990: 269). Bu yönde, cinsel tacizin nesnel ve öznel tanımlarında büyük boşluklar olduğu belirtilmektedir (Folgero ve Fleldstad, 1995; 300; Ilies ve diğerleri, 2003).

Cinselliğin belirli ifadelerin, taciz ya da oyun olarak nitelendirilmesi yalnızca cinsiyetler arasında farklılık göstermez. Bu kişilerin farklı özelliklerine göre de değişebilir. Bu yönde, bir cinsel ifade aynı örgütteki birisi tarafından yapıldığında şaka, bir başkası tarafından yapıldığında taciz olarak değerlendirilebilir (Giuffre ve Williams 1994; Schultz, 2003: 2159-2160). Örneğin, Giuffre ve Williams (1994), ABD'deki bazı restoranlardan topladıkları veriler ışığında çalışanların kendileriyle aynı "ırk, sınıf ve cinsel yönelime" sahip iş arkadaşlarının cinsel davranışlarını şaka ve olumlu olarak gördüklerini belirtmişlerdir. Buna karşın, çalışanlar aynı davranışları, kendilerinden farklı ırk, sınıf ve cinsel yönelime sahip çalışanlardan geldiğinde cinsel taciz olarak algılamaktadırlar (ayrıca bkz. Erickson, 2010).

Örgütlerde cinsellik yalnızca yönetimden habersiz şekilde ifade edilmez. Örgütlerde yönetim belirli cinselliklerin ifade edilmesini teşvik edilebilir. Örneğin, çalışanların cinselliği müşterilerle sorunsuz bir etkileşim kurmak için kullanılabilir (Brannan,
2005). Özellikle turizm ve eğlence sektörlerinde kadın çalışanların pasif cinselliklerinin işin parçası olduğu belirtilmiştir (Adkins, 1995). Bununla birlikte, hizmet etkileşimlerinde cinselliğin kullanımı kadın çalışanlarla sınırlı değildir. Erkek çalışanlardan da müşterilerle etkileşimlerinde örgütsel amaçlar için cinselliklerini kullanmaları beklenebilir. Brannan (2005), çağrı merkezlerinde yaptığı etnografik çalışmada erkek çalışanların kadın müşterilerle cinsel içerikli şakalar yaparak flörtleştiklerini, kadınların da erkek müşterilere karşı "dişil alımlılık ve sempatikliği" kullandıklarını belirtmiştir (ss. 433-434). Brannan (2005), kadın çalışanların erkek çalışanlara göre cinselliklerinin pasif bir biçimde kullanmalarından rahatsızlık duyduklarını, erkeklerinse kadın müşterilerle oyunsal olan cinselleşmiş hizmet ilişkilerinden memnun olduklarını belirtmiştir (ss. 433-434).

Örgütlerde cinsellik her zaman kadın çalışanları pasifize etmez. Kadın çalışanlar cinselliklerini kendi çıkarları için de kullanabilirler; bu durum, kadın çalışanlar için olumlu olabilir (Lerum, 2000: 15-24; Yelvington, 1996). Örneğin, Lerum (2000), iki restoran ve bir striptiz kulübünden topladığı verilere dayanarak kadın çalışanların erkek müşterilerle flörtleşmelerinin kadın çalışanlara müşterilerle olan etkileşimlerde daha fazla "denetim" ve güç sağladığını, onları hizmet etkileşimlerinde daha "görülebilir" ya da önemli yaptığını belirtmişstir (s. 180).

Ayrıca, yönetim, çalışan cinselliklerinin ifadeleriyle yalnızca müşterilerle olan etkileşimler kapsamında ilgilenmez. Yönetim, çalışanlar arasında da belirli cinsellikleri hoş görebilir. Örneğin, Fleming (2007), Avustralya'daki bir çağrı merkezinde yaptığı araştırmada yönetimin işyerinde eğlenceli ve özgürlükçü bir kültür oluşturmak adında "cinselliğe, parti yapmaya, iyi zaman geçirmeye" vurgu yaptığını belirtir (s. 252). Bu kültür kapsamında çalışanlar özellikle giyim, sosyalleşme ve flörtleşme konularında cinselliklerini ifade edebilmektedirler. Bazı çalışanlar bu ortamdan hoşnutturlar. Ancak, bazı kadın çalışanlar söz konusu kültürü tacizle ilişkili görerek desteklememektedir. Ayrıca, bazı çalışanlar cinselliğin söz konusu örgütteki ifadesini samimi görmemektedir; onlara göre bu cinsel ifadeler işi daha çekilebilir kılarak yöneticilerin elinde bir denetim aracı olmaktadır (Fleming, 2007: 251). Tüm bu tartışmalar örgütlerde cinselliğin farklı taraflar için net bir şekilde düzen kurucu ya da düzen bozucu olmadığını göstermektedir. 


\section{TARTIŞMA VE SONUÇ}

Cinsellik ve örgütler birbirlerini şekillendirirler. Örgütlerde cinsellik farklı şekillerde ifade bulur (Hearn ve Parkin, 1995: 63-127; Warhurst ve Nickson, 2009; Williams ve diğerleri, 1999). Bazı örgütler doğrudan cinsellik üzerine kurulmuşlarken - örneğin, striptiz barları - bazılarının cinsellikle bağlantısı dolaylıdır. Aynı zamanda, örgütlerde cinselliğin doğrudan ve dolaylı kullanımları belirsiz olabilir (Hearn ve Parkin, 1995: 68). Bazı örgütlerde cinselliğe belirli oranda hoşgörü gösterilebilirken bazılarındaysa sıfır hoşgörü gösterilir; bununla birlikte her örgütün bir şekilde cinsellikle bağlantısı vardır; diğer bir deyişle, tamamen cinselliğin yok edildiği bir örgüt yoktur (Burrell, 1984).

Genel olarak örgütlerde cinsellik düzen bozucu görülmektedir; bu kapsamda taciz, baskı ve dışlamayla ilişkilendirilmektedir. Ancak bu görüş kapsamında örgütlerde cinselliği tamamen ortadan kaldırma çabaları ters tepebilir. Örneğin, Elsesser ve Peplau (2006), ABD'de örgütlerde erkek ve kadın arkadaşlığını engelleyen etmenleri araştırdıkları çalışmalarında, bireylerin "normal arkadaşlık ilişkileri”nin romantik ilişki olarak algılanması ve arkadaşlar arasındaki şakalaşmalarının cinsel taciz diye nitelendirilmesi korkusunu örgütlerdeki erkekler ve kadınların arkadaşlık geliştirmelerinde önemli bir engel olarak göstermişlerdir (Elsesser ve Peplau, 2006: 1093). Bu yönde erkekler, cinsel taciz suçlamasına uğramamak için erkek arkadaşlarıyla paylaştıkları şakaları kadınlarla paylaşmama eğilimindedirler. Bu durumun sonucunda kadınlar da erkekleri kendileriyle olan sohbetlerinde sınırlanmış görmektedirler (Elsesser ve Peplau, 2006: 1090). Yazarlar, örgütlerdeki erkek ve kadın arkadaşlığının engellenmesini "cam tavan" kavramından esinlenerek "cam bölünme" (glass partition) olarak adlandırmışlardır (Elsesser ve Peplau, 2006: 1094).

Örgütlerde cinsellik her zaman düzen bozucu değildir. Cinselliğin Eros kapsamında oyunsal ifadeleri bireylerin sosyalleşmelerini ve iyi vakit geçirmelerini sağlayabilir. Ancak, cinselliğin oyunsal ifadeleri belirsizlik de barındırır. Örneğin, masum bir cinsel şaka kolaylıkla taciz olarak nitelendirilebilir. Bundan dolayı, örgütlerde cinselliğin incelenmesinde bütüncül görüş açılarından sakınılmalıdır.

Çoğunlukla, örgütlere cinsellik yazını, örgütlerdeki cinselliği örgütün büyüklüğü, hiyerarşisi (çalışanların örgütteki ast-üst ilişkisi), (Powell, 2001) erkek-kadın oranı (Gutek, 1985: 149; O'Leary-Kelly ve diğerleri,
2009: 510), örgüt kültürü ve iklimi (Mano ve Gabriel, 2006; Timmerman ve Bajema, 2000; Folgero ve Fleldstad, 1995; Willness ve diğerleri, 2007: 133-134) gibi soyut ve bütünleyici yapılar kapsamında ele alır. Örgütlerde cinsellik yazını, örgütlerde cinselliği yukarıda belirtilen soyut ve bütüncül kavramlarla incelediği için "gerçekte örgütlerde neler, neden" (Williams ve diğerleri, 1999: 81), "nasıl" yaşanıyor sorularına yanıt verememiştir. Soyut kavramlarla yapılan araştırmalar, örgütlerdeki cinselliğin etkilerini farklı örgütler ve de aynı örgütteki farklılıklar kapsamında ele alamamaktadır (Zelizer, 2009). Bu durum, cinselliğin değerlendirilmesinde yanıltıcıdır; çünkü bir örgütte "skandal olarak nitelendirilebilecek bir cinsellik diğer bir örgütte çalışma pratikleriyle yakın ilişkili olabilir" (Williams ve diğerleri, 1999: 91). Örneğin bir animatörün, turiste cinsel içerikli şaka yapması kabul edilebilir; ancak, bir doktorun hastasına cinsel içerikli şaka yapması kabul edilemeyecektir.

Örgütlerde cinsellik sosyalleşme, iyi zaman geçirme, verimlilik, kadın çalışanları baskılama gibi farklı örgütsel unsurlarla iç içedir. Bundan dolayı, örgütlerde cinselliğin düzen kurucu mu yoksa düzen bozucu mu olduğunu ele alacak çalışmalar, cinselliği diğer örgütsel unsurlardan bağımsız ele almamalıdır (Zelizer, 2009). Örgütlerde cinselliğin diğer örgütsel unsurlarla olan iç içeliği, çalışma pratikleri kapsamında değerlendirilebilecektir (Riach ve Wilson, 2014; Sullivan, 2014). Örgütlerdeki gündelik pratiklerin çoğu, çalışma pratiklerinden oluşur (Nicolini, 2012). Çalışma pratiklerinin incelenmesi farklı çalışanların birbirleriyle, yöneticileriyle ve müşterilerle hangi koşullarda ve hangi etkilerle etkileşimde bulunduklarını ele alır (bkz. Riach ve Wilson, 2014). Çalışma pratikleriyle örgütlerde cinselliğin incelenmesi ne soyut ve bütüncül yapılara ne de bireylerin öznel görüşlerine indirgenir (Riach ve Wilson, 2014). Çünkü çalışma pratiklerinin nasıl olması ve icra edilmesi gerektiği konusunda bireylerin belirli güçleri olmasına karşın, çalışma pratiklerini nasıl icra edecekleri ve bu kapsamda diğer çalışanlar ya da müşterilerle nasıl etkileşime geçecekleri konusunda sınırsız özgürlükleri yoktur (Feldman ve Pentland, 2003). Bu durum da genel olarak farklı örgütsel ortam ve pratiklerde hangi cinsel pratiklerin kabul edilebilir ya da kabul edilemez olduğunun belirlenmesinde belirli bir temel sağlamaktadır. Örgütlerde cinselliğin çalışma pratikleri kapsamında incelenmesi cinselliğin düzen kurucu ve/ya da düzen bozucu rolünü örgütlerdeki güç ve direniş unsurlarıyla olan bağlantılarıyla değerlendirebilecektir (Fleming, 2007; 
Riach ve Wilson, 2014). Çalışma pratiklerinin ele alınması için de alana yakın ve vakıf olmayı sağlayan nitel araştırmalar uygundur (Schatzki, 2005: 476).

\section{KAYNAKLAR}

Ackroyd, S. ve Thompson, P. (1999) Organizational Misbehaviour. London, Sage.

Adkins, L. (1995). Gendered Work: Sexuality, Family and the Labour Market, Buckingham: Open University Press.

Aquino, K., Sheppard, L., Watkins, M. B., O'Reilly, J. ve Smith, A. (2014) "Social Sexual Behavior at Work" Research in Organizational Behavior, 34: 217-236.

Bauman, Z. (2003) Modernlik ve Müphemlik. (Çeviren: i. Türkmen). İstanbul, Ayrıntı Yayınları.

Beatty, J. E. ve Torbert, W. R. (2003) "The False Duality of Work and Leisure" Journal of Management Inquiry, 12(3): 239-252.

Bell, E. ve Sinclair, A. (2014) "Reclaiming the Eroticism in the Academy" Organization, 21(2): 268-280.

Boyd, C. (2010) "The Debate over the Prohibition of Romance in the Workplace" Journal of Business Ethics, 97(2): 325-338.

Bowles, M. L. (1993) "Logos and Eros: the Vital Syzygy for Understanding Human Relations and Organizational Action" Human Relations, 46(11): 1271-1290.

Brannan, M. J. (2005) "Once more with Feeling: Ethnographic Reflections on the Mediation of Tension in a Small Team of Call Centre Workers" Gender, Work and Organization, 12(5): 420-439.

Brewis, J., Hampton, M. P. ve Linstead, S. (1997) "Unpacking Priscilla: Subjectivity and Identity in the Organization of Gendered Appearance" Human Relations, 50(10): 1275-1304.

Brewis, J. ve Linstead, S. (2000) Sex, Work and Sex Work. London, Routledge.

Britton, D.M. (1997) "Gendered Organizational Logic" Gender and Society, 11(6): 796-818.

Burrell, G. (1984) "Sex and Organizational Analysis" Organization Studies, 5(2): 97-118.

Burrell, G. (1992) The Organization of Pleasure, Critical Management Studies (ss.66-89). (Der.) M. Alvesson ve $\mathrm{H}$. Willmott, London, Sage.

Brewis, J. ve Linstead, S. (2000) Sex, Work and Sex Work, London, Routledge.

Brewis, J., Hampton, M. P. ve Linstead, S. (1997) "Unpacking Priscilla: Subjectivity and Identity in the Organization of Gendered Appearance" Human Relations, 50 (10): 1275-1304.

Carr, D. M. (2003) The Erotic World: Sexuality, Spiritiuality, and the Bible, Oxford, Oxford University Press.

Chodorow, N. J. (1985) "Beyond Drive Theory: Object Relations and the Limits of Radical Individualism" Theory and Society, 14(3): 271-319.

Collinson, D. L. (2002) "Managing Humour" Journal of Management Studies, 39(3): 271-288.

Dant, T. (2003) Critical Social Theory: Culture, Society and Critique, London, Sage.

Denissen, A. M. (2010) “Crossing the Line: how Women in the Building Trades Interpret and Respond Conduct at Work" Journal of Contemporary Ethnography, 39 (3): 297-327.

Duncan, W. J., Smeltzer, L. R. ve Leap, T. L. (1990) "Humour and Work: Applications of Joking Behavior to Management" Journal of Management, 16(2): 255278.

Elsesser, K. ve Peplau, L. A. (2006) “The Glass Partition: Obstacles to Cross-sex Friendship at Work" Human Relations, 59 (8): 1077-1100.

Ely, R. ve Padavic, I. (2007) "A Feminist Analysis of Organizational Research on Sex Differences" Academy of Management Review, 32(4): 1121-1143.

Erickson, K. A. (2010) Talk, Touch, and Intolerance: Sexual Harassment in an Overtly Sexualized Work Culture Içinde Gender and Sexuality in the Workplace: Research in the Sociology of Work, 20 (ss. 179-202), (Der.), C. L. Williams ve K. Dellinger, Bingley, Emerald.

Feldman, M. S. ve Pentland, B. T. (2003) "Reconceptualizing Organizational Routines as a Source of Flexibility and Change" Administrative Science Quarterly, 48(1): 94-118.

Fleming, P. (2007) "Sexuality, Power and Resistance in the Workplace" Organization Studies, 28(2): 239-256.

Folgero, I. S. ve Fjeldstad, I. H. (1995) "On Duty - Off Guard: Cultural Norms and Sexual Harassment in Service Organizations" Organization Studies, 16(2): 299-313.

Freud, S. (2004). Uygarlığın Huzursuzlukları (Çeviren: H. Barışcan), İstanbul, Metis Yayınları. 
Fromm, E. (1997) Sevme Sanatı (Çeviren: S. Budak), Ankara, Öteki Yayınevi.

Giddens, A. (2004) Modernliğin Sonuçları (Çeviren: E. Kuşdil), İstanbul, Ayrıntı Yayınları.

Giuffre, P. A. ve Williams, C. L. (1994) "Boundary Lines: Labeling Sexual Harassment in Restaurants" Gender and Society, 8 (3): 378-401.

Gordon, G. (2009) What is Play?: İçinde Search of a Definition. From Children to Red Hatters: Diverse Images and Issues of Play (ss. 1-13). (Der.) D. Kuschner. Maryland, University Press of America.

Gotham, K. F. ve Krier, D. A. (2008) From the Culture Industry to the Society of the Spectacle: Critical Theory and the Situationist International, İçinde Current Perspectives in Social Theory Vol: 25 (ss. 155192), (Der.), H. F. Dahms. Bingley, Emerald.

Gutek, B. A. (1985) Sex and the Workplace. California, Jossey-Bass.

Hancock, P. ve Tyler, M. (2001) Work, Postmodernism and Organization: A Critical Introduction. London, Sage.

Hearn, J.ve Parkin, W. (1995) Sex at Work. New York, St. Martin's Press.

Hearn, J. (2011) Sexualities, Work, Organizations, and Managements. İçinde Handbook of Gender, Work and Organization (ss. 299-314) (Der.), E. L. Jeanes, D. Knights ve P. Y. Martin. Chichester, John Wiley and Sons.

Huizinga, J. (2006) Homo Ludens: Oyunun Toplumsal Işlevi Üzerine bir Deneme (Çeviren: M. A. Kılıçbay), İstanbul, Ayrıntı Yayınları.

Ilies, R, Hauserman, N., Schwochau, S. ve Stibal, J. (2003) "Reported Incidence Rates of Work-related Sexual Harassment in the United States" Personel Psychology, 56: 607-631.

Jay, M. (2005) Diyalektik Imgelem: Frankfurt Okulu ve Toplumsal Araştırmalar Enstitüsünün Tarihi. İstanbul, Belge Yayınları.

Kellner, D. (2006). Frankfurt Okulu'nu Yeniden Değerlendirmek:Martin Jay'in Diyalektikimgelem'inin Eleştirisi. İçinde Frankfurt Okulu (ss. 134-164) (Der). H. E. Bağce. Ankara, Doğu Batı Yayınları

Koçak, O. (2008) Önsöz. (ss. 7-52). Akıl tutulması., İstanbul, Metis Yayınları.

Lerum, K. (2000) Doing the Dirty Work: Emotion Work, Professionalism, and Sexuality in a Customer Service Economy, Yayınlanmamış Doktora Tezi, Sosyoloji Bölümü, University of Washington.
Lerum, K. (2004) "Sexuality, Power, and Camaraderie in Service Work" Gender and Society, 18(6): 756-776.

Mainemelis, C. ve Ronson, S. (2006) “Ideas are Born in Fields of Play: Towards a Theory of Play and Creativity in Organizational Settings" Research in Organizational Behavior, 27: 81-131.

Mano, R. ve Gabriel, Y. (2006) “Workplace Romances in Cold and Hot Organizational Climates: the Experience of Israel and Taiwan" Human Relations, 59(1): 7-35

Marcuse, H. (1997) Tek-Boyutlu Insan (Çeviren: A. Yardımlı). İstanbul, İdea Yayınevi.

Marcuse, H.(1998) Eros ve Uygarlık: Freud Üzerine Bir Inceleme (Çeviren: Aziz Yardamlı). İstanbul, İdea Yayınevi.

Martin, J. (2000) "Hidden Gendered Assumptions in Mainstream Organizational Theory and Research" Journal of Management Inquiry, 9(2): 207-216.

Martin, P. Y. (2006) "Practising Gender at Work: Further Thoughts on Reflexivity" Gender, Work and Organization, 13(3): 254-276.

Nicolini, D., 2012. Practice Theory, Work, and Organization. Oxford, Oxford University Press.

O'Leary-Kelly, A. M., Bowes-Sperry, L., Bates, C. A. ve Lean E. R. (2009) "Sexual Harassment at Work: A Decade (Plus) of Progress Journal of Management, 35(3): 503-536.

Quinn, R. E. (1977) “Coping with Cupid: the Formation, Impact, and Management of Romantic Relationships in Organizations" Administrative Science Quarterly, 22(1): 30-45.

Pierce, C. A. ve Aguinis, H. (2009) "Moving Beyond Legal-centric Approach to Managing Workplace Romance" Human Resource Management, 48(3): 447464.

Plumwood, V. (2004) Feminizm ve Doğaya Hükmetmek (Çeviren: B. Ertür). İstanbul, Metis Yayınları.

Powell, G. N. (2001) “Workplace Romances between Senior-level Executives and Lower-level Employees" Human Relations, 54(11): 1519-1544.

Pringle, R. (2005) Sexuality at Work. İçinde Critical Management Studies: a Reader (ss. 284-303) (Der.) C. Grey ve H. Willmott. New York, Oxford University Press.

Riach, K. ve Wilson, F. (2007) “Don't Screw the Crew: Exploring the Rules of Engagement in Organizational Romance" British Journal of Management, 18(1): 7992. 
Riach, K. ve Wilson, F. (2014) "Bodyspace at the pub: sexual orientation and organizational space" Organization, 21(3): 329-345.

Rickert, J. (1986) "The Fromm-Marcuse Debate Revisited" Theory and Society, 15(3): 351-400.

Sandelands, L. (2010) "The Play of Change" Journal of Organizational Change Management, 23(1): 71-86.

Schatzki, T. R. (2005) "The Sites of organizations" Organization Studies, 26(3), 465-484.

Schultz, V. (2003) "The Sanitized Workplace" Yale Law Journal, 112(8): 2061-2193.

Shilling, C. (1997) "Emotions, Embodiment and the Sensation of Society" Sociological Review, 45(2): 195219.

Shilling, C. ve Mellor, P. A. (2010) "Sociology and the Problem of Eroticism" Sociology, 44(3): 435-452.

Simmell, G. (2009) Bireysellik ve Kültür (Çeviren: T. Birkan), İstanbul, Metis Yayınları.

Sullivan, K. R. (2014) "With(out) pleasure: Desexualization, Gender and Sexuality at Work" Organization, 21(3): 346-364.

Sutton-Smith, B. (2001) The Ambiguity of Play, USA, Harvard University Press.

Toulmin, S. (2002) Kozmopolis: Modernitenin Gizli Gündemi (Çeviren: H. Arslan), İstanbul, Paradigma Yayıncilık.

Trethewey, A. (1999) “Disciplined Bodies: Women's Embodied Identites at Work" Organization Studies, 20(3): 423-450.

Timmerman, G. ve Bajema, C. (2000) "The Impact of Organizational Culture on Perceptions and Experiences of Sexual Harassment" Journal of Vocational Behavior, 57(2): 188-205.
Wagner, P. (1996) Modernliğin Sosyolojisi (Çeviren: M. Küçük). İstanbul, Sarmal Yayınevi.

Walsh, Philip (2008) Herbert Marcuse and Contemporary Social Theory, Içinde Current Perspectives in Social Theory Vol: 25 (ss. 235-260), (Der.), H. F. Dahms. Bingley, Emerald.

Wang, N. (2000) Tourism and Modernity: A Sociological Analysis, Oxford, Pergamon.

Warhurst, C. ve Nickson, D. (2009) "Who's got the Look? Emotional, Aesthetic and Sexualzed Labour in Interactive Services" Gender, Work and Organization, 16(3): 385-404.

Weber, M. (2006) Sosyoloji Yazıları (Çeviren: T. Parla), İstanbul, Illetişim Yayınları.

Williams, C. L., Giuffre, P. A. ve Dellinger, K. (1999) "Sexuality in the Workplace: Organization Control, Sexual Harrassment and the Pursuit of Pleasure" Annual Review of Sociology, 25(1): 73-93.

Willness, C. R., Steel, P. ve Lee, K. (2007) "A Metaanalysis of the Antecedents and Consequences of Workplace Sexual Harassment" Personel Psychology, 60(1): 127-162.

Wilson, F. (2015) "Romantic Relationships at Work" International Journal of Management Reviews, 17: 1-19.

Yelvington, K. A. (1996) "Flirting in the Factory" Journal of the Royal Anthropological Institute, 2(2): 313-333.

Zelizer, V. A. (2009) Intimacy in Economic Organizations İçinde Economic Sociology of Work, 28 (ss. 23-55), (Der.), N. Bandelj, Bingley, Emerald.

Zilbersheid, U. (2009a) "The Utopia of Herbert Marcuse Part 1" Critique, 36(3): 403-419.

Zilbersheid, U. (2009b) "The Utopia of Herbert Marcuse Part 2: Freudianism" Critique, 37(1): 81-98. 